\title{
TRABALHO E SER SOCIAL: UMA REFLEXÃO ONTOLÓGICA DO TRABALHO NA RELAÇÃO HOMEM X NATUREZA
}

\author{
WORK AND BE SOCIAL: AN ONTOLOGICAL REFLECTION OF THE \\ WORK PROCESS IN MAN X NATURE
}

\author{
Ana Karina da Silva Alves ${ }^{1}$ \\ Ruth Maria de Paula Gonçalves ${ }^{2}$ \\ Frederico Jorge Ferreira Costa ${ }^{3}$
}

\section{RESUMO}

O artigo tem por objetivo apresentar elementos para a compreensão do caráter ontológico do trabalho na relação homem x natureza. $\mathrm{O}$ aporte teórico utilizado compreende a ontologia marxiana, estudos de autores clássicos do campo, a exemplo de George Lukács, ao recuperar o legado de Marx, contemplando ainda as ideias de István Mészáros e de autores contemporâneos que tratam apropriadamente desse referencial, como Sérgio Lessa e Ivo Tonet. Serão apresentados aspectos importantes da ontologia do ser social, com o objetivo de trazer para o centro o debate sobre a análise marxiana do trabalho, buscando entendê-lo como intercâmbio entre 0 homem e a natureza, protoforma da atividade humana, um processo no qual o homem transforma a natureza e, ao mesmo tempo, se transforma ao explorar suas capacidades físicas e intelectuais. A partir do trabalho, ato gênese do ser social, o homem utiliza os recursos da natureza, atendendo necessidades e abrindo novas possibilidades para a vida humana.

Palavras-chaves: Ontologia marxiana - Ser social - Trabalho .

\section{ABSTRACT}

The article aims to provide elements for understanding the ontological character of the work in the man $x$ nature. The theoretical approach includes the Marxian ontology, studies of classical authors from the field, like George Lukács, to recover the legacy of Marx, still contemplating the ideas of István Mészáros and contemporary authors appropriately treat this reference as Sérgio Lessa Ivo Tonet. Will be presented important aspects of the ontology of social being, in order to bring to the center the debate on Marx's analysis of the work, trying to understand it as exchange between man and nature, protoform of human activity, a process in which man transforms nature and at the same time, turns to explore their physical and intellectual abilities. From the work, act genesis of social being, man uses nature's resources, meeting needs and opening up new possibilities for human life.

Keywords: Marxian ontology - Be social - Work. 


\section{INTRODUÇÃO}

Este artigo versa sobre o trabalho enquanto atividade permanente e categoria basilar na constituição do ser social, levando em consideração seu caráter ontológico na relação homem $x$ natureza, tendo em vista que impulsiona a dinâmica da vida em sociedade e incide de forma decisiva no processo de ruptura do homem com as barreiras naturais.

Nesse sentido, apresenta, em linhas gerais, a essência ontológica do homem, a qual é fundada no trabalho e, através da qual ele transforma o meio natural e a si mesmo. Para tanto, os estudos sobre a ontologia marxiana resgatada por Lukács, iluminado pelos lineamentos teóricos de Marx, nos servirão de base para este estudo, assim como as contribuições de István Mészáros e de estudiosos que tratam apropriadamente desse referencial, como Sérgio Lessa e Ivo Tonet.

Com esse intuito, foi utilizada a pesquisa de natureza qualitativa, com recorrência aos materiais bibliográficos e documentais já produzidos a respeito das categorias apreendidas.

\section{DESENVOLVIMENTO}

Marx (1982, p.45) parte do pressuposto de que a concepção histórica humana é materialista, asseverando "a existência de indivíduos humanos vivos". Portanto, os homens produzem seus meios de vida, a partir das condições postas pela natureza e, diferente dos animais, modificam-na de acordo como suas necessidades, através de suas ações no decorrer da história.

Sob esse prisma, o autor define o trabalho como a atuação do homem sobre a natureza externa para dar utilidade aos seus recursos, como forma de satisfazer as necessidades humanas, configurando-se como dispêndio de força humana, física e mental sobre a natureza, para a produção de valores de uso.

LESSA (2007, p.36), afirma, a partir dos pressupostos de Lukács, que o trabalho é a forma primária de todo o agir humano e se apresenta como fundamento ontológico de todas as formas da práxis social. 
Com base no legado de Marx, o autor considera que o trabalho é a relação do homem com a natureza, e afirma que através do trabalho, o homem vive em constante modificação do meio natural e de si mesmo, distanciando-se cada vez mais do ser natural, regido por leis biológicas, constituindo a processualidade do ser social. Dito de outro modo, o trabalho se torna resultado de um processo entre o homem e a natureza, no qual esta é regulada e transformada pela ação do homem.

De acordo com (LUKÁCS, 2007, p.05), tal processo tem o objetivo de transformar objetos naturais em valores de uso, ou seja, em produtos que o homem usa para a reprodução de sua existência. Por conseguinte, através do trabalho, o homem passou a se relacionar consigo e com os outros homens, criando o ser social, que possibilitou o agir coletivo e o desenvolvimento da sociedade (MARX, 1978, p.126).

Nesta perspectiva, trazemos a contribuição de ENGELS (1876) ao afirmar que o homem foi utilizando e modificando a natureza através do trabalho. Esse autor afirma que não só o trabalho, mas também a palavra articulada foi um dos estímulos principais sob que possibilitou que o cérebro do macaco se transformasse gradualmente em cérebro humano.

Da mesma forma que o desenvolvimento gradual da linguagem está necessariamente acompanhado do correspondente aperfeiçoamento do órgão do ouvido, assim também o desenvolvimento geral do cérebro está ligado ao aperfeiçoamento de todos os órgãos dos sentidos. (ENGELS, 1876, p. 272).

Todo esse processo foi fundamental para que, tanto o homem quanto a própria sociedade se desenvolvesse como um todo, uma vez que, devido ao domínio que o homem teve sobre a natureza, com o desenvolvimento da mão, através do trabalho, ele ampliou seus horizontes e descobriu nos objetos, novas propriedades que até então não conhecia.

Vale ressaltar o caráter teleológico (que na perspectiva de Lukács 2007, representa o estudo filosófico dos fins, objetivo) dessa atividade humana, intercâmbio com a natureza, cujas características centrais a diferenciam da atividade realizada pelos animais. Com efeito, $\operatorname{MARX}$ (2003, p. 211-212) reconhece que "o que distingue o pior arquiteto da melhor abelha é que ele figura 
na mente sua construção antes de transformá-la objetivamente em realidade." Ao término do processo aparece um resultado que já existia antes idealmente na imaginação do trabalhador.

Ou seja, através do trabalho, o homem não só realiza uma transformação da forma da matéria natural, ele efetua, ao mesmo tempo, na matéria, o seu objetivo. Por isso, dizemos que ele - o trabalho - é uma posição teleológica, posta a partir de causalidades dadas que limitam o campo de ação do indivíduo.

No trabalho estão presentes os fundamentos e elementos constitutivos do processo histórico, quais sejam: a teleologia e a causalidade, que é divida em causalidade dada (natural) e causalidade posta (modificada pelo homem). A síntese desses dois fundamentos é a objetivação ou finalização do trabalho. Para LUKÁCS (1979, p. 17):

[...] com o ato da posição teleológica do trabalho, temos em si o ser social. O processo histórico da sua explicitação, contudo implica a importantíssima transformação desse ser em-si num ser para-si; e, portanto, implica a superação tendencial das formas dos conteúdos de ser meramente naturais em formas e conteúdos sociais mais puros, mais específicos.

lluminado pelos lineamentos teóricos de Marx, e baseando-se em seu complexo categorial, o autor vai desenvolver a ontologia do ser social, na qual o trabalho configura no ato-gênese do homem. Dessa forma, LUKÁCS (2007, p. 45) postula:

É anunciada a categoria ontológica do trabalho: através dele realiza-se, no âmbito do ser material uma posição teleológica que dá origem a uma nova objetividade. Assim, o trabalho torna-se modelo de toda práxis social, na qual, com efeito - mesmo através de mediações às vezes muito complexas - sempre são transformadas em realidade posições teleológicas, em termo que, em última análise, são materiais.

A ontologia lukacsiana tem o objetivo de reafirmar a possibilidade ontológica da emancipação humana, partindo do pressuposto de que essa constante busca é o caminho para a superação da alienação, do capitalismo no sentido de eliminar a exploração do homem pelo homem.

LUKÁCS (2007, p.11) também afirma a existência de três esferas ontológicas, articuladas entre si, a saber: a esfera inorgânica (ou mineral), a esfera biológica (da vida) e o ser social. É importante salientar que, para o autor, o ser social depende das outras esferas, uma vez que para que a socialização 
seja compreendida é preciso entender que entre esta e a natureza há uma relação efetiva.

A esfera inorgânica ou mineral limita-se ao processo de tornar-se e permanecer mineral, pois não possui vida em sua especificidade. Dela fazem parte os seres inorgânicos. Acerca dessa esfera, LESSA (2007, p. 22) afirma que "seu processo de transformação, sua evolução, nada mais é senão um movimento pelo qual algo se transforma em algo distinto."

A esfera biológica, por sua vez, possui a especificidade da "reprodução da vida", elemento que Lukács considera fundamental na esfera orgânica, tendo em vista que os seres orgânicos passam pelo mesmo processo de todos os outros seres humanos (nascem, crescem, reproduzem-se e morrem).

Dessa forma, o homem pertence à esfera da vida, mas não perde a condição de ser orgânico em sua evolução, tendo o ser social, sua origem em um processo evolutivo, em que ele consegue dar um salto qualitativo, ontológico que o diferencia do ser orgânico.

Nesse sentido, LUKÁCS (2007, p.225) afirma que existe entre as três esferas, uma ruptura ontológica, concluindo que o ser orgânico jamais se transformará em social, ou o inorgânico em biológico, pois desde o início da formação de novas categorias, há um corte na processualidade das categorias preexistentes, caracterizando essa ruptura.

Vale ressaltar que, não obstante a ruptura, as esferas ontológicas continuam a se desenvolver, sendo apenas interrompidas para o aperfeiçoamento de novas categorias. Com isso, LUKÁCS (2007, p.226), afirma que "[...] o ser em seu conjunto é visto como um processo histórico [...]."

Destarte, Marx e Lukács entendem que o salto ontológico é o momento da ruptura de uma categoria que dá origem a novas categorias, caracterizando então, um processo histórico. Em consonância com a perspectiva marxista, Silva (2005, p.18) infere que esse salto ontológico é uma consequência do trabalho consciente, que faz com que o homem se distancie da natureza imediata. Nas palavras de LESSA (2007, p. 141):

Trata-se mesmo, de um salto: o surgimento da espécie humana não configura uma necessidade da evolução biológica nem o desdobramento de uma programação genética - é uma autêntica ruptura nos mecanismos e regularidades naturais. $\mathrm{O}$ surgimento da vida trouxe à existência uma nova categoria, a reprodução biológica; de modo 
análogo, a gênese do ser social corresponde ao aparecimento de uma categoria radicalmente nova, que não pode ser derivada da natureza: a reprodução social.

É válido ressaltar que nesse ponto a consciência exerce um papel fundamental, pois é através dela que ocorre o distanciamento da atividade inicial de intercâmbio da natureza sem, contudo, anular sua origem ontológica em relação ao trabalho consciente.

Nessa perspectiva, LESSA \& TONET (2008, p.18) asseveram que:

[...] a transformação da natureza é um processo muito diferente das ações das abelhas e formigas. Em primeiro lugar porque a ação e seu resultado são sempre projetados na consciência antes de serem construídos na prática. É essa a capacidade de idear (isto é, de criar ideias), antes de objetivar (isto é, construir objetiva ou materialmente) que funda, para Marx, a diferença do homem em relação à natureza, a evolução humana.

É possível afirmarmos, então, que trabalho é exclusivamente humano, pois existe "planejamento que antecede a ação" (LESSA, 2007, p. 37). Ou seja, o homem elabora na mente sua construção antes de transformar a realidade. Assim, o homem se diferencia do animal através da prévia ideação do trabalho que será realizado.

Essa prévia ideação, apesar de ocorrer em um momento abstrato, deve ser efetivada, ou seja, o criador deve colocá-la em prática para que seja originado o objeto que, por sua vez, de acordo com LESSA (2007, p.38), é ontologicamente diferente de quem o criou.

Tal distinção, segundo LUKÁCS (2007, p.138), é o que explica a alienação do ser social em relação ao objeto, pois como explica LESSA (2007, p.26-27), "[...] a alienação é a distinção concreta, real, ontológica (isto é, no plano do ser) entre o sujeito e o objeto que vem a ser pela objetivação de uma prévia ideação. "[...] Ser humano, para Lukács, significa uma crescente capacidade de objetivar/alienar - isto é, transformar o mundo segundo finalidades socialmente postas."

Com efeito, entre sujeito e objeto, há uma unidade, nunca identidade, considerando que o novo objeto, idealmente previsto, uma vez criado, passa a ser movido por uma relação de causas e efeitos, externa à consciência. Como reconhece LESSA (2007, p. 137), "[...] à esfera subjetiva, a consciência se contrapõe o mundo objetivo.". 
Como já foi dito anteriormente, o homem transforma a natureza a partir de suas necessidades, para atingir seus objetivos. Nesse sentido, o trabalho estrutura o intercâmbio social entre o homem e a natureza, revelando-se como resultado desse processo.

Assim, entre o ser social e a natureza existe uma relação que se estabelece a partir do trabalho e das necessidades do homem para manter sua existência. Ao mesmo tempo em que ele transforma a natureza, transforma a si mesmo, possibilitando a transição do ser biológico para o social. Daí, a afirmação de LUKÁCS (2004), de que o trabalho possui um caráter expressamente transicional.

SILVA (2005, p.18) afirma que o trabalho, enquanto apropriação consciente dos elementos naturais para a satisfação das necessidades do homem torna-se condição natural da vida humana e que, através da ontologia marxista, o homem age teleologicamente, através do trabalho, para responder a uma determinada causalidade dada.

Reportando-nos a ANTUNES (2000, p.136), percebemos que o trabalho "possibilita o salto ontológico das formas pré-humanas para o ser social". O autor considera que, através do trabalho, "um pôr teleológico que (previamente) o ser social tem ideado em sua consciência", esse ser social cria e recria suas próprias condições de reprodução.

Ainda na concepção de ANTUNES (1995, p.80), o trabalho embora seja "ineliminável" da condição humana, não é um objeto natural, e sim uma ação fundamental para estabelecer as relações entre o homem e a natureza, e entre as sociedades e a natureza. A esse respeito, LESSA (2007, p. 134) considera que:

As leis sociais referem-se a fenômenos e processos produzidos pela ação humana, e, portanto, são mutáveis e suprimíveis em função desta ação; as leis naturais referem-se a fenômenos e processos que independem da atuação humana, ainda que sobre eles os homens possam agir. Em outras palavras, como o homem não criou a natureza pode transformá-la, porém, jamais, aboli-la.

MEDEIROS \& MACÊDO (2007, p.27) concordam com os autores mencionados acima e acrescentam que o trabalho é elemento integrante da vida das pessoas, seja ele em sua forma assalariada, ou não, pois, na sociedade atual ele possibilita a construção de uma identidade, tanto profissional como pessoal do 
indivíduo, tendo um significado essencial no universo da sociabilidade humana, caracterizando a forma de vida das pessoas.

Entendemos, a partir daí, que o trabalho não significa apenas um meio de sobrevivência, mas de construção da própria identidade, já que a profissão caracteriza um modo de vida, tendo espaço central na vida do ser humano, uma vez que é dedicada maior parte do seu tempo a ele.

\section{CONCLUSÃO}

Apesar do trabalho configurar-se como atividade vital e condição eterna da vida humana, no seio da sociedade capitalista ele é realizado de forma que suas potencialidades emancipatórias sejam negadas, o que faz com que os indivíduos que o realizam não se reconheçam nele, como sujeitos.

Tal conclusão é reforçada por SILVA (2005, p.40), quando afirma que o trabalho em si é a essência da gênese humana, mas perdeu seu caráter humanizador quando foi apropriado pelo capital.

O capitalismo, por sua vez, se apresenta como um sistema contraditório, cujo trabalho é subordinado ao capital. Em sua forma contemporânea, o capital em sua luta desenfreada por reproduzir-se, enfrenta uma crise estrutural. MÉSZÁROS (2000, p.127).

Essa crise, segundo o autor, permite ao capital se utilizar de artimanhas ídeo-políticas, no sentido de manipular as consciências e se perpetuar como sistema dominante. Com isso, o trabalhador permanece sem se apropriar minimamente do que produz, precisamente porque aquilo que produz é para fins de comercialização, atendendo a reprodução metabólica do capital, não para atender as necessidades do homem.

A contradição capital $\mathrm{x}$ trabalho acarreta no crescimento das desigualdades entre as classes, engendra a divisão cabeça-mão, a qual constitui a desarticulação entre trabalho manual e trabalho intelectual, impedindo o pleno desenvolvimento das esferas do agir, pensar e sentir.

Diante desse cenário, MÉSZÁROS (2000, p.128), adverte que o sistema capitalista impede ideologicamente que a classe trabalhadora se reconheça como capaz de mudar o rumo de sua história e promover a emancipação humana. Em suma, com base nesses pressupostos o autor 
reconhece que a única alternativa para a continuidade da humanidade é a transformação socialista como forma de superação do sistema do capital.

\section{REFERÊNCIAS BIBLIOGRÁFICAS}

ANTUNES, R. Adeus ao trabalho?: ensaio sobre as metamorfoses e a centralidade do mundo do trabalho. 6 ${ }^{\text {a }}$ Ed. Campinas-SP: Cortez, 1995.

. Os sentidos do trabalho: ensaio sobre a afirmação e a negação do trabalho. 3를 Ed. São Paulo: Boitempo Editorial, 2000.

ENGELS, Friedrich. Sobre o papel do trabalho na transformação do macaco em homem. 1876. Edição eletrônica: Ridendo Castigat Mores. Rocketdition de 1999. Disponível em: <http://www.jah.org>. Acesso em: 16 fev. 2012.

LESSA, Sérgio. Para compreender a ontologia de Lukács. 3. ed. rev. e amp. ljui. Ed: Unijui, 2007.

; TONET, Ivo. Introdução à filosofia de Marx. São Paulo:

expressão Popular, 2008.

LUKÁCS, György. Ontologia do Ser Social - Os Princípios

Ontológicos Fundamentais de Marx. São Paulo: Livraria Editora Ciências Humanas, 1979.

Ontologia del Ser Social: El Trabajo - textos ineditos en castellano. Buenos Aires: Ediciones Herramienta, 2004.

As bases ontológicas do pensamento e da atividade do homem. In: COUTINHO, C. N.; NETTO, J. P. (Org.). O jovem Marx e outros escritos de filosofia. Rio de Janeiro: Editora UFRJ, 2007.

MARX, Karl. Manuscritos econômico-filosóficos. Lisboa: Edições, 1964.

O capital. Livro I, capítulo VI (inédito). São Paulo: Editora da USP, 1978.

A ideologia alemã. Tradução de José Carlos Bruni e Marco Aurélio Nogueira. São Paulo: Livraria e Editora Ciências Humanas, 1982.

. Contribuição à crítica da economia política. Tradução de Maria Helena Barreiro Alves [a partir da tradução francesa]. 2. ed. São Paulo: Martins Fontes, 2003. (Coleção 
MEDEIROS, Luiza Ferreira de Rezende; MACEDO, Kátia Barbosa. Profissão: catador de material reciclável, entre o viver e o sobreviver. [Documento eletrônico] Revista Brasileira de Gestão e Desenvolvimento Regional, v. 3, n. 2, 2007. Disponível em: <http://www.rbgdr.net>. Acesso em: 20 fev. 2013.

MÉSZÁROS, I. A crise estrutural do capital. Revista Outubro, São Paulo: Instituto de Estudos Socialistas, 2000.

SILVA, Solonildo A. V. O caminho lato sensu da precarização do trabalho docente universitário na Uece. Dissertação (Mestrado). Curso de Mestrado Acadêmico em Políticas Públicas e Sociedade do Centro de Humanidades e Centro de Estudos Sociais Aplicados, da Universidade Estadual do Ceará, 2005.

1 Mestranda em Serviço Social, Trabalho e Questão Social pela Universidade Estadual do Ceará (UECE). Membro do Grupo de Pesquisa: Ontologia do Ser Social, História, Educação e Emancipação Humana - GPOSSHE . E-mail: karina.sa@outlook.com

${ }^{2}$ Doutora em Educação pela Universidade Federal do Ceará (UFC). Membro do Grupo de Pesquisa: Trabalho, Educação e Luta de Classes. Email: ruthm@secrel.com

${ }^{3}$ Doutor em Educação pela Universidade Federal do Ceará (UFC). Grupo de Pesquisa: Ontologia do Ser Social, História, Educação e Emancipação Humana GPOSSHE . E-mail: frederico1917@yahoo.com.br

RECEBIDO EM: outubro/2014

APROVADO EM: novembro /2014 